\title{
O PRONAF COMO POLÍTICA DE APOIO AOS ASSENTADOS DO PROGRAMA NACIONAL DE REFORMA AGRÁRIA
}

\section{The Pronaf as the Support Policy to the Settlers of National Program of Agrarian Reform}

Prof. Dr. Luis Lopes Diniz Filho

Pós-Graduação em Geografia da Universidade Federal do Paraná Centro Politécnico - Jardim das Américas, Cx. Postal: 19001, CEP: 81531-970 - Curitiba (PR), Brasil Tel: (+55 41 ) 33613050 - diniz.ufpr@gmail.com

Rosana Zafalon

Mestranda Pós-Graduação em Geografia da Universidade Federal do Paraná rosanazafalon@gmail.com

\section{aaAaa}

\begin{abstract}
Resumo
O Programa Nacional de Fortalecimento da Agricultura Familiar - Pronaf, foi instituído nos anos 90 para dar suporte financeiro aos agricultores familiares. Em 1999, o Pronaf foi estendido aos assentados do Programa Nacional de Reforma Agrária. Buscou-se, desse modo, integrar todos os agricultores familiares num único programa, o que facilitaria a concessão de crédito. Ao Pronaf caberia promover a sustentabilidade dos assentamentos via aumento da produtividade e da renda das famílias. Tal objetivo, no entanto, ainda não foi alcancado no PA Marimbondo Japira, pois o crédito de custeio, mais utilizado, não é suficiente para ampliar a produção e renda. Desse modo, o acesso à modalidade investimento é apontado como o meio mais eficaz na promoção da sustentabilidade do assentamento.
\end{abstract}

Palavras-chave: Crédito rural. Agricultura familiar. Reforma agrária. Pronaf.

\begin{abstract}
The Pronaf - National Program for the Strengthening of Family Farming, was instituted in 90 years to provide financial support to family farmers. In 1999, Pronaf was extended to settlers of National Program of Land Reform. The intention was to integrate all the farmers in a single program, which would facilitate the granting of credit. Therefore, the responsibility of Pronaf was provide the sustentability of settlements by increasing the family production and incoming. But this objective was not achieved yet in the PA Marimbondo Japira, because the credits are not enough to increase the settlers production and incoming. The access to investment model is showed like the most efficient instrument in the promotion of settlement sustentability.
\end{abstract}

Key words: Rural Credit. Family agriculture. Land reform. Pronaf.

\section{Resumen}

El Programa Nacional de Fortalecimiento de la Agricultura Familiar - PRONAF, fue instituido en los años 90 para dar suporte financiero a los agricultores familiares. En 1999, el PRONAF fue extendido a los beneficiarios del Programa Nacional de Reforma Agraria. Se busca, de ese modo, integrar todos a los agricultores familiares en un único programa, lo que facilitaría la concesión de crédito. Al PRONAF le tocaría promover la sostenibilidad de los asentamientos vía aumento de la productividad y el ingreso de las familias. Tal objetivo, en tanto aún no fue alcanzado en el PA Marimbondo Japira, ya que el crédito de costo, más utilizado, no es suficiente para ampliar la producción e ingreso. De ese modo, el acceso a la modalidad inversión es apuntado como el medio más eficaz en la promoción para la sostenibilidad del asentamiento.

Palabras-clave: Crédito rural. Agricultura familiar. Reforma agraria. Pronaf. .

\section{aaAaa}

Revista da ANPEGE, v. 7, n. 8, p. 69-79, ago./dez. 2011.

ISSN 1679-768 X @ 2003, Associação Nacional de Pesquisa e Pós-Graduação em Geografia. Todos os direitos reservados. 


\section{INTRODUÇÃO}

O Programa Nacional de Fortalecimento da Agricultura Familiar - Pronaf instituído em 1996, é a primeira política pública federal especificamente voltada para o segmento dos produtores familiares brasileiros (MATTEI, 2006, p. 13). Desde 1998, com a extinção do Procera (linha de crédito específica para os assentados do Programa Nacional de Reforma Agrária - PNRA) e a incorporação de seus beneficiários ao Pronaf, diversas pesquisas têm sido realizadas para avaliar os possíveis benefícios deste para a reforma agrária. Nesse contexto, o presente artigo visa expor os resultados de um estudo de caso sobre os efeitos da aplicação do Pronaf no Projeto de Assentamento Marimbondo.

Esse assentamento está localizado parte no município de Japira e parte no município de Ibaiti, ambos no estado do Paraná. Compõe-se de 72 lotes, mas, para fins desta pesquisa, foram entrevistadas somente as 46 famílias que residem na área pertencente à Japira, segundo delimitação adotada pela prefeitura municipal. As entrevistas foram realizadas no mês de Janeiro do ano de 2008 e os resultados obtidos foram cotejados com os de estudos mais amplos sobre o desempenho do Pronaf e da política de reforma agrária (ZAFALON, 2009).

\section{POLÍTICA AGRÍCOLA E AGRICULTURA FAMILIAR NO BRASIL}

No Brasil, até o final da década de 1960, os agricultores familiares eram denominados predominantemente pelo termo "campesinato", sendo que os anos 70 trouxeram para esse grupo social uma nova qualificação: a de pequena produção, que para muitos está vinculada a transformações ocorridas no cenário político brasileiro com a desarticulação dos movimentos reivindicatórios que tinham na identidade camponesa a sua marca de resistência e de luta. (BASTOS, 2005)

Todavia, tem sido muito difícil estabelecer um conceito preciso de agricultura familiar, em vista de sua grande heterogeneidade social e produtiva (GERMER, 1996; CERQUEIRA e ROCHA, 2002, ALTAFIN, 2003; SCHNEIDER, 2003). Sobre isso, OLIVEIRA (2004), com referência nos estudos de LAMARCHE (1993), afirma que, em algumas situações, a exploração familiar é o segmento de frente do desenvolvimento agrícola, mas em outras ela permanece arcaica e fundada numa economia de subsistência. Em algumas situações, ainda, a exploração familiar é reconhecida como a única forma social de produção capaz de satisfazer às necessidades essenciais da sociedade, enquanto que em outras é excluída e desacreditada. Essas situações revelam a enorme capacidade de adaptação da agricultura familiar, sendo que sua heterogeneidade seria reflexo das diferentes faces de um mesmo objeto e não de objetos intrinsecamente distintos. Dessa forma, a agricultura familiar deve ser analisada em seu conjunto, mas tendo em vista a diversidade que lhe é própria. Assim, para compreender seu funcionamento, é preciso evidenciar as diferentes lógicas em função das quais o agricultor determina suas escolhas fundamentais, sendo essas lógicas definidas em relação aos sistemas de produção, aos sistemas fundiários e aos familiares, além dos sistemas de valores e os de representação. (OLIVEIRA, 2004)

Assim, nos anos 90, quando o governo federal decidiu encetar políticas específicas de apoio à agricultura familiar (algo até então inédito nesse nível de governo), havia necessidade de definir um conceito operacional de sistemas agrários, sendo que a delimitação da agricultura familiar adotada baseou-se em estudos do Incra/FAO fundamentados numa definição desenvolvida na França (OLIVEIRA, 2004).

Além disso, esse estudo indicou que a agricultura familiar brasileira é praticada em três modalidades: a) a agricultura familiar consolidada; b) a agricultura familiar de transição; c) a agricultura familiar periférica. De acordo com SILVA (1999), a agricultura familiar consolidada é aquela integrada ao mercado, com acesso a inovações tecnológicas e a políticas públicas, funcionando assim, majoritariamente, em padrões empresariais. Já a agricultura familiar em transição é caracterizada pelo acesso parcial as inovações tecnológicas e ao mercado e pelo não acesso a maioria das políticas e programas governamentais, não estando, portanto, consolidadas como empresas, mas, apresentan- 
do grande potencial para isso. Finalmente, a agricultura familiar periférica é definida como aquela que opera sob condições de infraestrutura inadequada e que depende de políticas governamentais para sua integração produtiva à economia. Ainda segundo esse autor, o Pronaf foi concebido para atender ao conjunto dos agricultores familiares, porém, com prioridade para aqueles chamados de periféricos e em transição. Essa prioridade não está explícita nos documentos, mas pode ser evidenciada principalmente no Pronaf - Infraestrutura, linha de financiamento que se destinava aos municípios mais carentes .

Nesse contexto, o objetivo geral estabelecido pelo Pronaf era "propiciar condições para o aumento da capacidade produtiva, a geração de empregos e a melhoria da renda, contribuindo para a melhoria da qualidade de vida e a ampliação do exercício da cidadania por parte dos agricultores familiares" (SILVA, 1999, p. 6). Esse objetivo deveria ser atingido pela realização de vários objetivos específicos, conforme segue:

a) ajustar políticas públicas à realidade da agricultura familiar;

b) viabilizar a infraestrutura rural necessária à melhoria do desempenho produtivo e da qualidade de vida da população rural;

c) fortalecer os serviços de apoio ao desenvolvimento da agricultura familiar;

d) elevar o nível de profissionalização de agricultores familiares, para lhes propiciar novos padrões tecnológicos e de gestão; e

e) favorecer o acesso de agricultores familiares e suas organizações aos mercados de produtos e insumos (SILVA, 1999, p. 6-7).

O Pronaf inclui, além do apoio financeiro às atividades exploradas pelos agricultores familiares, conhecido como Pronaf $\mathrm{C}$, projetos especiais que atendem segmentos específicos de agricultores familiares. É válido ressaltar que no seu ano de criação (1996), realizaram-se apenas operações relativas ao crédito de custeio, sendo que a ampliação para as demais áreas (investimento, infraestrutura e serviços municipais, capacitação e pesquisa) ocorreu apenas a partir de 1997, quando o Pronaf ganhou mais dimensão e passou a operar de forma integrada em todo o país (MATTEI, 2006). Para os objetivos deste estudo, porém, cumpre enfocar apenas os efeitos da aplicação do Pronaf nos assentamentos de reforma agrária, o que será feito por meio de um estudo de caso sobre a área do Projeto de Assentamento Marimbondo pertencente ao município de Japira (PR).

\section{ORIGEM DOS ASSENTADOS DO PA MARIMBONDO E FORMA DE AQUISIÇÃO DOS LOTES}

A primeira questão da entrevista tinha por objetivo identificar a origem da família, se rural ou urbana, estabelecendo desse modo, aquelas com vínculo a terra anterior ao assentamento bem como as outras que nunca haviam exercido atividade agrícola.

Assim, perguntou-se aos cônjuges qual era sua origem/residência antes do assentamento. Definiram-se as seguintes categorias: Classe 1 para aqueles com origem rural; Classe 2 para os de origem urbana; Classe 3 para quem residia em área urbana mas que havia nascido e passado certo tempo em área rural; por fim, a Classe 4 designa aqueles em que cada um dos cônjuges tem origem diferente, um de área rural e outro urbana. A grande maioria afirmou sempre ter residido em áreas rurais, apresentando vínculos com a agricultura antes do assentamento. 
Tabela 1 - Origem dos cônjuges

\begin{tabular}{|l|r|r}
\hline \multicolumn{1}{|c|}{ ORIGEM } & № DE CASAIS & \multicolumn{1}{c}{ PERCENTUAL } \\
\hline Classe 1 & 34 & 74 \\
\hline Classe 2 & 6 & 13 \\
\hline Classe 3 & 4 & 8,7 \\
\hline Classe 4 & 2 & 4,3 \\
\hline TOTAL & 46 & 100 \\
\hline
\end{tabular}

Fonte: Pesquisa de campo, 2008.

Essa é uma questão importante, pois a inclusão de desempregados urbanos nos projetos de assentamento (bastante favorecida por organizações como o MST, que recrutam muitos de seus membros junto a esse grupo social) é um fator que pode contribuir para que haja venda e arrendamento ilegais de lotes. Como afirma CAUME (2004, p. 5), "os comprometidos com a bandeira da reforma agrária não podem ignorar esse grave fenômeno que contribui, enormemente, para deslegitimar a luta social pela terra". Nesse sentido, os dados da tabela mostram que o PA em questão possui atualmente um perfil de assentados que, em 74,0\% dos casos, são de origem exclusivamente rural. Mas talvez não fosse essa a realidade no momento da implantação do assentamento, visto que, das 46 famílias entrevistadas, apenas 16 declararam ser remanescentes do processo de ocupação e desapropriação da antiga Fazenda Jaboticabal e Marimbondo, enquanto a maior parte, 26 famílias, afirmaram terem "comprado" o direito de exploração dos lotes, segundo a tabela abaixo.

Tabela 2 - Forma de aquisição dos lotes pelos seus atuais moradores

\begin{tabular}{l|r|r}
\hline \multicolumn{1}{c|}{ TIPOS DE AQUISIÇÃo } & NÚMERO DE FAMÍLIAS & \multicolumn{1}{c}{ PERCENTUAL (\%) } \\
\hline Famílias que participaram do processo de ocupação & 16 & 34,8 \\
\hline Famílias que "compraram" o direito de exploração & 26 & 56,6 \\
\hline Famílias que ocuparam lotes abandonados & 2 & 4,3 \\
\hline $\begin{array}{l}\text { Famílias de antigos trabalhadores da fazenda } \\
\text { desapropriada }\end{array}$ & 2 & 4,3 \\
\hline TOTAL: & 46 & 100 \\
\hline
\end{tabular}

Fonte: Pesquisa de campo, 2008.

Conforme os dados levantados pela pesquisa, esse processo de compra e venda do direito de exploração de lotes teria começado antes mesmo da instituição do PA Marimbondo, em julho de 1996, e continua em curso até os dias atuais, como se verifica na tabela abaixo:

Tabela 3 - Tempo de aquisição dos lotes pelos assentados que declararam terem "comprado" o direito de exploração de antigos moradores

\begin{tabular}{l|r|r}
\hline TEMPO DE AQUISIÇÃO & N ${ }^{\circ}$ DE FAMÍLIAS & PERCENTUAL (\%) \\
\hline Menos de 1 ano & 2 & 7,7 \\
\hline De 1 a 3 anos & 5 & 19,2 \\
\hline De 3 a 5 anos & 2 & 7,7 \\
\hline De 5 a 8 anos & 5 & 19,2 \\
\hline De 8 a 10 anos & 1 & 3,9 \\
\hline De 10 a 12 anos & 3 & 11,5 \\
\hline De 12 a 15 anos & 8 & 30,8 \\
\hline TOTAL & 26 & 100,0 \\
\hline
\end{tabular}

Fonte: Pesquisa de campo, 2008. 
Portanto, embora aproximadamente três quartos dos assentados do PA Marimbondo atualmente tenham nascido e residido em áreas rurais antes de obterem seus lotes, não se pode saber se era essa a realidade entre os primeiros assentados, visto que a evasão é muito alta nesse assentamento. E essa prática continuou em curso mesmo após a saída dos primeiros assentados, visto que dois dos atuais moradores afirmaram que já são os quartos a morarem em seus respectivos lotes.

Ora, como a maioria dos atuais assentados pagou para obter o direito de uso dos lotes, é pertinente concluir que, hoje, a maior parte desse projeto de assentamento não está beneficiando a população rural mais carente, ao contrário do que se espera de um programa de reforma agrária. A esse respeito, uma informação bastante surpreendente levantada pela pesquisa de campo foi o valor que tem sido pago pelos lotes, equiparado ao preço de lotes regulares fora de projetos de assentamento. A última compra registrada, a menos de um ano da realização da pesquisa, declarada pelo atual morador, é do valor de R $\$ 70.000,00$. Outra família, há cerca de 2,5 anos no assentamento, declarou ter desembolsado $\mathrm{R} \$ 80.000,00$ por seu lote. Mas, quando perguntadas sobre o valor pago por seus lotes, muitas famílias preferiram não declarar nenhum valor. E algumas das que mencionaram disseram que o valor informado não era o real, mas aquele, sempre muito abaixo do verdadeiro, declarado para fins de fiscalização pelo Incra no momento das vistorias.

Sobre a prática de venda de lotes nos assentamentos, a Instrução Normativa n. 47 de 16/09/2008, que trata das diretrizes para supervisão da situação ocupacional em projetos de reforma agrária, retomada de parcelas ocupadas irregularmente e sua destinação para assentamento de agricultores, estabelece como parcela irregular, entre outras situações, aquela que tenha sido objeto de compra e venda relativa à terra nua e/ou benfeitorias e estabelece que os assentados que abandonarem suas parcelas sem apresentar justificativas ao Incra ou que tiverem as mesmas retomadas pela Autarquia, em função de irregularidades cometidas ou descumprimento de quaisquer cláusulas contratuais, serão excluídos do PNRA e não poderão mais ser beneficiários desse programa. Mas, para tanto, é preciso que sejam constatadas essas irregularidades durante as vistorias realizadas pelo Incra, durante as quais são levantadas informações referentes às parcelas irregularmente ocupadas, via transmissão sem anuência do Incra, identificando-se o assentado original transmitente, o ocupante atual e data da ocupação. A transferência dos lotes é registrada em Ata da Associação de Moradores do PA, e posteriormente efetivada pelo Incra.

Em suma, verifica-se que, no PA Marimbondo, a maioria dos lotes trocou de mãos de forma ilegal e é hoje ocupado por famílias que, embora majoritariamente oriundas de áreas rurais, já dispunham de algum patrimônio antes de integrarem o assentamento. Trata-se, pois, de famílias de agricultores familiares já inseridas no mercado de produtos agropecuários antes de se mudarem para essa área. As informações referentes ao tempo de exercício na atividade agropecuária atestam isso, conforme a próxima tabela.

Tabela 4 - Tempo de exercício da atividade agropecuária

\begin{tabular}{l|r|r}
\hline CLASSES DE FAMÍLIAS & No. DE FAMÍLIAS & PERCENTUAL (\%) \\
\hline Sempre exerceu atividade agropecuária & 32 & 69,6 \\
\hline Só após a entrada no assentamento & 12 & 25,0 \\
\hline Retomou a atividade agropecuária após a entrada no assentamento & 2 & 4,4 \\
\hline TOTAL & 46 & 100 \\
\hline
\end{tabular}

Fonte: Pesquisa de campo, 2008.

Como se pode ver, pouco mais de dois terços dos entrevistados disse sempre ter exercido atividades agropecuárias, um quarto só começou a atuar nesse ramo após sua entrada no assentamento, e há ainda um pequeno grupo que tem origem rural, mas morou e exerceu atividades urbanas durante alguns anos, retomando à atividade agropecuária ao ingressar no assentamento. Nesse sentido, a comparação dos dados das duas últimas tabelas demonstra que os lotes que compõem esse assenta- 
mento estão inseridos no mercado de terras (embora ilegalmente), motivo pelo qual atraem famílias que não pertencem ao universo dos sem-terra ou dos desempregados urbanos, mas da agricultura familiar. Ainda assim, a pluriatividade foi detectada em 32,6\% das famílias do PA Marimbondo no município de Japira, conforme as entrevistas de campo .

\section{RENDA DAS FAMÍLIAS NO PA MARIMBONDO JAPIRA}

O valor do salário mínimo vigente em janeiro de 2008, quando foi realizado o trabalho de campo, era de $\mathrm{R} \$ 380,00$. Pouco mais da metade dos assentados declarou possuir renda familiar variável entre três e cinco salários mínimos, enquanto $45,6 \%$ das famílias auferiam uma renda que não ultrapassava dois salários mínimos. Um único assentado declarou renda familiar superior a cinco salários mínimos, podendo-se então concluir que a média de renda dos assentados é baixa.

Tabela 5 - Renda familiar

\begin{tabular}{l|r|r}
\multicolumn{1}{c|}{ FAIXAS DE RENDA } & \multicolumn{1}{c|}{ N $^{\circ}$ DE FAMílIAS } & \multicolumn{1}{c}{ PERCENTUAL (\%) } \\
\hline Até 2 salários mínimos & 21 & 45,6 \\
\hline De 3 a 5 salários mínimos & 24 & 52,2 \\
\hline Acima de 5 salários mínimos & 1 & 2,2 \\
\hline TOTAL & 46 & 100 \\
\hline
\end{tabular}

Fonte: Pesquisa de campo, 2008.

Entre as vinte e uma famílias que declararam renda familiar de até dois salários mínimos, três possuem um membro aposentado, seis são beneficiárias do programa Bolsa Família e cinco contam com ambos os benefícios. Buscou-se também estimar a renda domiciliar per capita dos assentados a partir dos dados de renda e número de membros de cada família.

Se tomarmos como referência a maior renda possível em cada faixa, entre as famílias com renda familiar de até dois salários mínimos, oito famílias podem ser classificadas como pobres. Já no grupo de renda familiar entre três e cinco salários mínimos, apenas duas famílias se enquadram nessa categoria. Desse modo, das quarenta e seis famílias pesquisadas, dez, cerca de $22 \%$, podem ser classificadas como pobres. No entanto, se adotarmos como referência a menor renda possível, no caso, três salários mínimos na faixa de renda entre três e cinco salários, essas duas famílias não seriam classificadas mais como pobres e sim como indigentes .

Desse modo, uma estimativa precisa da renda e número de pobres e/ou indigentes no assentamento pesquisado não poderia ser alcançada. De fato, a dificuldade de determinar uma renda agrícola precisa se deve à variação sazonal dos preços e custos dos produtos, como também à parcela dos produtos que é destinada ao autoconsumo, não sendo assim declarada como parte da renda total (SOUZA e NASCIMENTO, 2007). Porém, pode-se afirmar que a maioria das famílias do PA Marimbondo Japira se enquadra no grupo com renda domiciliar per capita de até R\$ 405. Esse valor está muito abaixo do rendimento médio real domiciliar per capita calculado pelo IBGE, que era de R\$ 720,00 no ano de 2008, segundo a publicação Síntese de Indicadores Sociais (IBGE, 2008, p. 93), e de R \$ 822,55 em outubro desse mesmo ano, segundo a Pesquisa Mensal de Emprego - PME.

\section{MODALIDADES DO CRÉDITO DO PRONAF ADOTADAS}

Das quarenta e seis famílias entrevistadas, quarenta utilizam ou já utilizaram pelo menos uma vez o crédito do Pronaf, em ambas as modalidades, custeio e/ou investimento, o que corresponde a $87 \%$ das famílias. No entanto, a modalidade mais utilizada foi o custeio agrícola, conforme a tabela abaixo.

Dentre as famílias que já utilizaram a modalidade crédito do programa (num total de 39), doze afirmaram ter adotado o crédito apenas uma vez, nos anos de 1998 a 2004. A justificativa para essa opção foi a dificuldade de pagamento causada por problemas de ordem climática que afetaram a 
colheita (75\%), comprometendo o pagamento do empréstimo, bem como a falta de documentação (25\%) por serem famílias que estão no assentamento há apenas três anos, aproximadamente.

Tabela 6 - Adoção do crédito do PRONAF por modalidade

\begin{tabular}{l|r|r}
\hline MODALIDADES & N DE FAMíLIAS & PERCENTUAL (\%) \\
\hline Custeio & 24 & 52,2 \\
\hline Investimento & 1 & 2,2 \\
\hline Ambos & 15 & 32,6 \\
\hline Nenhum & 6 & 13 \\
\hline Total & 46 & 100 \\
\hline
\end{tabular}

Fonte: Pesquisa de campo, 2008.

Quanto à modalidade investimento, só começou a ser adotada na área de estudo a partir de 2005. Das dezesseis famílias que possuem essa linha de crédito, nove conseguiram o empréstimo em 2005, uma em 2006, e seis em 2007 (37,50\%), tempo relativamente curto para medir as melhorias geradas pelo programa.

Quanto aos valores dos empréstimos, na modalidade custeio eles variaram entre $\mathrm{R} \$ 1.840,00$ a $\mathrm{R} \$ 5.000,00$, numa média de aproximadamente $\mathrm{R} \$ 2.780,00$. Já na linha de investimento, entre $\mathrm{R} \$ 6.000,00$ e $\mathrm{R} \$ 9.800,00$, numa média de $\mathrm{R} \$ 6.818,00$ por empréstimo, conforme a tabela abaixo.

Tabela 7 - Valores declarados quanto aos empréstimos nas modalidades custeio e investimento

\begin{tabular}{c|c|c|c}
\hline CUSTEIO & VALORES (R\$) & INVESTIMENTO & VALORES (R\$) \\
\hline 1 & $1.840,00$ & 1 & $6.000,00$ \\
\hline 2 & $2.000,00$ & 2 & $6.500,00$ \\
\hline 3 & $3.000,00$ & 3 & $7.500,00$ \\
\hline 4 & $4.950,00$ & 4 & $8.650,00$ \\
\hline 5 & $5.000,00$ & 5 & $9.000,00$ \\
\hline---- & --- & 6 & $9.800,00$ \\
\hline MÉDIA & $2.780,00$ & MÉDIA: & $6.818,00$ \\
\hline
\end{tabular}

Fonte: Pesquisa de campo, 2008.

Em termos de aplicação do crédito, verificou-se que os assentados que optaram pela modalidade custeio investiram preferencialmente na produção de milho e no cultivo do café mediante a compra de mudas e insumos agrícolas. Como terceira opção, aparece a pecuária, através da reforma de pastos e cercas. Como aplicações isoladas, aparecem os cultivos de arroz, cana-de-açúcar, uva e eucalipto, citados apenas uma vez cada um pelos assentados. E ainda, uma família que afirmou não ter utilizado o crédito na produção agropecuária, mas nas chamadas "despesas de casa". E essa mesma família não conseguiu pagar seu empréstimo.

Por sua vez, quanto às aplicações na modalidade investimento, a pecuária aparece como principal forma de aplicação, subdividindo-se ainda na compra de gado leiteiro e de corte. Em seguida, aparecem a produção de café (mudas, insumos e construção de terreiro para a secagem) e a aquisição de equipamento de irrigação para o cultivo de milho. 
Tabela 8 - Principais aplicações do crédito de custeio

\begin{tabular}{l|r|r}
\hline \multicolumn{1}{c|}{ CULTIVOS } & №. DE MENSURAÇÕES* & PERCENTUAL (\%) \\
\hline Milho & 19 & 39,6 \\
\hline Café & 17 & 35,4 \\
\hline Arroz & 1 & 2,1 \\
\hline Cana-de-açúcar & 1 & 2,1 \\
\hline Eucalipto & 1 & 2,1 \\
\hline Uva & 1 & 2,1 \\
\hline Pecuária & 7 & 14,5 \\
\hline Despesas de casa** & 1 & 2,1 \\
\hline TOTAL & 48 & 100 \\
\hline
\end{tabular}

Fonte: Pesquisa de campo, 2008.

Nota: *Algumas famílias apontaram mais de um cultivo na aplicação do crédito, por isso, o número de mensurações é maior que o de famílias. ** Em relação às “despesas de casa”, o assentado referia-se principalmente à alimentação.

Tabela 9 - Principais aplicações do crédito de investimento

\begin{tabular}{l|r|r}
\hline \multicolumn{1}{c|}{ PRODUTOS } & № DE MENSURAÇÕES* & \multicolumn{1}{c}{ PERCENTUAL (\%) } \\
\hline Pecuária leiteira & 10 & 62,5 \\
\hline Pecuária de corte & 4 & 25 \\
\hline Café & 1 & 6,25 \\
\hline Equipamento de irrigação & 1 & 6,25 \\
\hline TOTAL & 13 & 100 \\
\hline
\end{tabular}

Fonte: Pesquisa de campo, 2008.

\section{EFEITOS DO PRONAF SOBRE A PRODUTIVIDADE E A RENDA}

Quanto aos efeitos do Pronaf sobre a renda, vale destacar que, em estudo realizado em oito estados brasileiros com produtores agrícolas familiares que receberam e que não receberam crédito do Pronaf na safra 2000/2001, KAGEYAMA (2003) concluiu que esse programa não esteve associado à maior renda familiar, mas apresentou forte correlação com as variáveis tecnológicas e com a produtividade agrícola. No PA Marimbondo verificou-se também pouca correlação entre uso do crédito do Pronaf e aumento de renda e mesmo da produtividade. Quando perguntados sobre o aumento da produção e da renda após a adoção do programa, 31 assentados (77,5\% do total) afirmaram ter havido um pequeno aumento. No entanto, nenhum deles soube quantificar essa ampliação.

Os pouco mais de $20 \%$ que afirmaram não ter havido aumento da produção e da renda após a adoção do Pronaf pertencem ao grupo de assentados que, conforme visto na tabela 6, utilizaram apenas a modalidade custeio do programa. Segundo declararam nas entrevistas, os resultados foram negativos pelo motivo principal da perda da produção acarretada por fatores climáticos, como secas que afetaram as plantações de milho e geadas que atingiram os cafezais. Afirmações questionáveis, pois a região não apresenta uma estação seca definida e ocorrem apenas geadas esporádicas, sendo que, no período tomado como referência para a pesquisa, de 1999 a 2007, não houve períodos tão longos de estiagem e apenas uma geada significativa no ano 2000. Outros apontaram ainda o fato de produzirem pouco, não gerando lucros elevados com o cultivo de milho.

Ao contrário dos primeiros, todos aqueles que optaram pela linha de investimento e custeio afirmaram ter havido aumento de produção e de renda, ainda que não mensurado quantitativamente. Esse é um resultado previsível, já que o investimento, por definição, é a aplicação de capital com vistas à ampliação da capacidade produtiva.

Perguntou-se também quais foram as mudanças geradas pelo Pronaf. Os assentados da modalidade custeio afirmaram que a adoção do crédito facilitou o plantio, principalmente de milho, 
e o cuidado com as lavouras de café, por meio da aquisição de insumos agrícolas. Aqueles que possuem também crédito na modalidade investimento ressaltaram que só foi possível diversificar sua produção investindo em pecuária graças ao crédito do Pronaf.

Tabela 10 - Aumento de produção e renda

\begin{tabular}{l|r|r}
\hline & N DE FAMíLIAS & PERCENTUAL (\%) \\
\hline Sim & 31 & 77,5 \\
\hline Não & 9 & 22,5 \\
\hline TOTAL & 40 & 100 \\
\hline
\end{tabular}

Fonte: Pesquisa de campo, 2008.

Uma pequena parcela afirmou não ter havido mudanças positivas com a adoção do programa, pois não conseguiram quitar seus empréstimos. Houve também aqueles que não souberam mencionar as possíveis mudanças, uma vez que realizaram a primeira operação de crédito havia menos de um ano.

Tabela 11 - Mudanças geradas pela adoção do crédito do PRONAF

\begin{tabular}{l|r|r}
\hline \multicolumn{1}{c|}{ MUDANÇAS } & N DE FAMÍLIAS & PERCENTUAL (\%) \\
\hline Facilidade para a aquisição de sementes, insumos e bovinos & 30 & 75 \\
\hline Sem mudanças positivas e dívidas a serem quitadas & 8 & 20 \\
\hline Não sabem (pouco tempo da realização do empréstimo) & 2 & 5 \\
\hline TOTAL & 40 & 100 \\
\hline
\end{tabular}

Fonte: Pesquisa de campo, 2008.

\section{PERSPECTIVAS E EFICIÊNCIA DO PRONAF NA ÁREA DE ESTUDO}

Também foi perguntado às famílias se elas pretendiam continuar usando o crédito. Conforme a tabela abaixo, vinte e oito responderam afirmativamente, sendo que um número menor afirmou não querer realizar um novo empréstimo. Por fim, houve quatro que disseram "talvez".

O grupo que afirmou não querer realizar um novo empréstimo é composto por famílias que tiveram dificuldades ou mesmo não conseguiram quitar seus empréstimos anteriores. O grupo que respondeu "talvez" apresentou como justificativa o excesso de burocracia para a tomada do crédito e o medo de não conseguirem pagar suas dívidas.

Tabela 12 - Adoção futura de créditos do PRONAF

\begin{tabular}{l|r|r}
\hline & N DE FAMÍLIAS & PERCENTUAL (\%) \\
\hline Sim & 28 & 70 \\
\hline Não & 8 & 20 \\
\hline Talvez & 4 & 10 \\
\hline TOTAL & 40 & 100 \\
\hline
\end{tabular}

Fonte: Pesquisa de campo, 2008.

Com relação à eficiência na aplicação dos recursos, as entrevistas de campo procuraram detectar possíveis usos não produtivos, quer fossem parciais ou totais, da aplicação do crédito no assentamento. Sendo essa uma prática que viola os contratos de tomada de crédito, procurou-se fazer uma avaliação por meio de perguntas indiretas, ou seja, correlacionando as datas e valores da adoção do Pronaf às da aquisição de automóveis. Os dados mostram que em seis famílias essas informações são coincidentes, de modo que o desvio de aplicação do crédito pode ter acontecido, embora seja apenas uma hipótese sugerida pelos dados. 
Tabela 13 - Possíveis casos de uso não produtivo do crédito do PRONAF no PA MARIMBONDO JAPIRA

\begin{tabular}{l|r|r|r|r}
\hline CASOS & $\begin{array}{c}\text { VALOR DO CRÉDITO } \\
\text { (R\$) }\end{array}$ & $\begin{array}{c}\text { ANO DA TOMADA DO } \\
\text { CRÉDITO }\end{array}$ & $\begin{array}{c}\text { VALOR DO VÉ́CULO } \\
\text { ADQUIRIDO (R\$) }\end{array}$ & $\begin{array}{c}\text { ANO DE AQUISIÇÃO DO } \\
\text { VEÍCULO }\end{array}$ \\
\hline 1. & $4.000,00^{*}$ & 2007 & $2.000,00$ & 2007 \\
\hline 2. & $6.000,00^{* *}$ & 2006 & $9.000,00$ & 2006 \\
\hline 3. & $6.000,00^{* *}$ & 2006 & $3.000,00$ & 2006 \\
\hline 4. & $6.000,00^{* *}$ & 2005 & $3.500,00$ & 2005 \\
\hline 5. & $7.500,00^{* *}$ & 2005 & $3.000,00$ & 2005 \\
\hline 6. & $3.000,00^{*}$ & 2004 & $2.000,00$ & 2004 \\
\hline
\end{tabular}

Fonte: Pesquisa de campo, 2008.

Nota: * Créditos na modalidade custeio. $* *$ Créditos na modalidade investimento

\section{PERMANÊNCIA NO ASSENTAMENTO}

A última questão feita às famílias dizia respeito à intenção delas em permanecer ou não no assentamento. A grande maioria, mais de $80 \%$, afirmou não pretender deixar seus lotes devido à identificação pessoal com a vida no campo. Outros afirmaram estarem dispostos a "vender" seus lotes de acordo com a oferta recebida. E um pequeno grupo de três assentados diz ter intenção de deixar o assentamento e ir morar em áreas urbanas.

Tabela 14 - Intenções das famílias em relação ao assentamento

\begin{tabular}{l|r|r}
\hline \multicolumn{1}{c|}{ INTENÇÕES } & N DE FAMÍLIAS & PERCENTUAL (\%) \\
\hline Permanência & 37 & 80,4 \\
\hline Venda de acordo com a oferta & 6 & 13,1 \\
\hline Mudança para áreas urbanas & 3 & 6,5 \\
\hline TOTAL & 46 & 100 \\
\hline
\end{tabular}

Fonte: Pesquisa de campo, 2008.

Esse resultado é coerente com as informações levantadas sobre a origem geográfica dos assentados e sua experiência com a agropecuária, posto que, conforme já analisado, a grande maioria dos assentados do PA Marimbondo é oriundo da zona rural e sempre se dedicou às atividades agropecuárias, embora quase um terço das famílias sejam pluriativas. A comparação dessas informações com as da tabela acima indica que a reforma agrária é vista pela maioria dos assentados como uma estratégia para viabilizar sua permanência no campo e, consequentemente, no modo de vida rural. Mesmo aqueles que admitem a intenção de "vender" o lote por uma boa oferta podem estar interessados em permanecer no espaço rural, pois o dinheiro auferido com a venda pode ser utilizado para a compra de uma propriedade rural em outro lugar. Apesar disso, vale lembrar que, embora o número de assentados que manifestou interesse em mudar-se para áreas urbanas seja bastante pequeno, não é possível saber onde foram residir aqueles primeiros assentados que venderam seus lotes ilegalmente. Finalmente, vale ressaltar que esses dados reforçam a avaliação de que esse assentamento de reforma agrária, ao invés de beneficiar a população rural mais carente, tem sido utilizado preponderantemente por agricultores familiares que já dispunham de certo patrimônio e que se mudaram para lá visando permanecer no campo e na agricultura.

\section{CONSIDERAÇÕES FINAIS}

São comuns as notícias de que o PNRA apresenta problemas relacionados à evasão de assentados e também à baixa renda e baixa produção nos assentamentos, sendo que este estudo demonstrou que tais problemas estão muito presentes no PA Marimbondo Japira. Já o Pronaf se propõe 
justamente a aumentar a capacidade produtiva, a geração de emprego rural e a melhoria da renda dos agricultores familiares. $\mathrm{O}$ estudo de caso realizado mostra que esse programa pode contribuir para a melhoria das condições de vida das famílias através do financiamento auferido e do aumento da renda e da produção.

No entanto, como o Pronaf trouxe poucos benefícios, já que o aumento de produção e renda mostrou-se ainda incipiente, não sendo nem quantificado pelas famílias pesquisadas, o programa não tem sido totalmente eficaz em promover a inclusão econômica e social dos assentados do PA Marimbondo. Com efeito, para tornar a agricultura familiar competitiva, um dos objetivos do Pronaf, seria necessário que houvesse independência em relação aos subsídios estatais, e isso ainda não aconteceu no assentamento em questão. Além disso, o número de assentados que trabalha fora do estabelecimento indica que o programa ainda não conseguiu atingir plenamente seus propósitos.

\section{REFERÊNCIAS BIBLIOGRÁFICAS}

ALTAFIN, I. G. Sustentabilidade, políticas públicas e agricultura familiar: uma apreciação sobre a trajetória brasileira. Brasília, 2003. 225p. Tese (Doutorado em Desenvolvimento Sustentável) - Universidade de Brasília.

BASTOS, F. Ambiente institucional no financiamento da agricultura familiar: avanços e retrocessos. Natal, 2005. Tese (Doutorado em Ciências Sociais) - Universidade Federal do Rio Grande do Norte.

CAUME, D. J. Reforma agrária na contemporaneidade brasileira: novos termos para um velho debate. Revista da UFG. v. 7, n.1, jun. 2004. Disponível em: http:// www.proec.ufg.br> Acesso em: out. 2007

CERQUEIRA, P. S.; ROCHA, A. G. A agricultura familiar e o Pronaf: elementos para uma discussão. Bahia Análise \& Dados, Salvador, v.12, n.3, p.105-117, dez. 2002.

GERMER, C. A irrelevância prática da agricultura familiar para o emprego agrícola. Curitiba: UFPR, 1996. 14 p.

IBGE. Síntese de indicadores sociais: uma análise das condições de vida da população brasileira. Rio de Janeiro: IBGE, 2008 (Estudos e Pesquisas: Informação Demográfica e Socioeconômica, n. 23).

KAGEYAMA, A. Produtividade e renda na agricultura familiar: efeitos do Pronaf - crédito. Agricultura em São Paulo, São Paulo: IEA, 2003. V.50, n.2, p.1-13.

LAMARCHE, H. (coord.). Agricultura Familiar: comparação internacional. v. 1. Uma realidade multiforme. Campinas: Unicamp. 1993 (Coleção Repertórios).

MATTEI, L. Pronaf 10 anos: mapa da produção acadêmica. Brasília: MDA, 2006.

OLIVEIRA, F. A. B. Análise da contribuição do Programa Nacional de Fortalecimento da Agricultura Familiar para a sustentabilidade do assentamento Lagoa da Serra, Caucaia - CE. Fortaleza, 2004. 120 p. Dissertação (Mestrado em Desenvolvimento e Meio Ambiente) - Universidade Federal do Ceará.

SCHNEIDER, S. A pluriatividade na agricultura familiar. Porto Alegre: Editora da UFRGS, 2003.

SILVA, E. R. A. Programa Nacional de Fortalecimento da Agricultura Familiar: relatório técnico das ações desenvolvidas no período 1995-1998. Brasília: IPEA, 1999.

SOUZA, M. NASCIMENTO, Carlos Alves do. Ocupações e rendas das famílias rurais e agrícolas no estado do Paraná. Revista Paranaense de Desenvolvimento, Curitiba, n.112, jan/jun. 2007. p. 73-91

ZAFALON, R. Análise do desempenho do Pronaf no Projeto de Assentamento Marimbondo Japira PR. Curitiba, 2009. 86p. Monografia de Conclusão de Curso (Bacharelado em Geografia) - Universidade Federal do Paraná.

Trabalho enviado em dezembro de 2011

Trabalho aceito em janeiro de 2011 